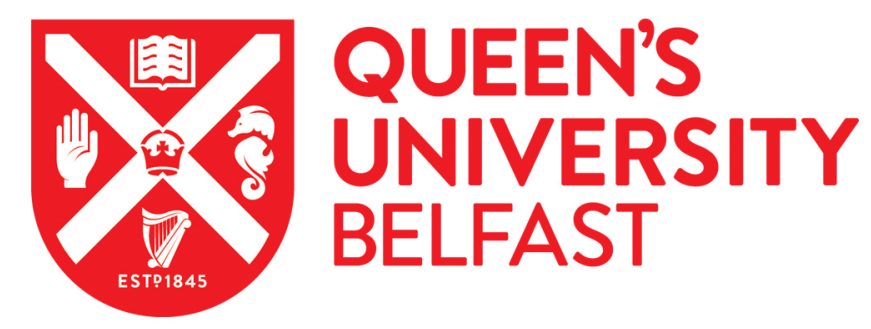

\title{
Birthweight and aerobic fitness in adolescents: the Northern Ireland Young Hearts Project
}

Boreham, C. A., Murray, L., Denman, D., Davey Smith, G., Savage, M., \& Strain, J. J. (2001). Birthweight and aerobic fitness in adolescents: the Northern Ireland Young Hearts Project. Public Health, 115(6), 373-379.

\section{Published in:}

Public Health

Queen's University Belfast - Research Portal:

Link to publication record in Queen's University Belfast Research Portal

\section{General rights}

Copyright for the publications made accessible via the Queen's University Belfast Research Portal is retained by the author(s) and / or other copyright owners and it is a condition of accessing these publications that users recognise and abide by the legal requirements associated with these rights.

Take down policy

The Research Portal is Queen's institutional repository that provides access to Queen's research output. Every effort has been made to ensure that content in the Research Portal does not infringe any person's rights, or applicable UK laws. If you discover content in the Research Portal that you believe breaches copyright or violates any law, please contact openaccess@qub.ac.uk. 


\title{
Birthweight and aerobic fitness in adolescents: the Northern Ireland Young Hearts Project
}

\author{
CA. Boreham *, L Murray ${ }^{2}$, D Dedman ${ }^{3}$, G Davey Smith ${ }^{3}$, JM Savage ${ }^{4}$ and JJ Strain ${ }^{5}$ \\ ${ }^{1}$ Sports Studies, University of Ulster, Northern Ireland, UK; ${ }^{2}$ Department of Epidemiology and Community Health, \\ The Queen's University' of Belfast, Northern Ireland, UK; and ${ }^{3}$ Department of Social Medicine, University of Bristol, UK; \\ ${ }^{4}$ Department of Child Health, The Queens University of Belfast, Northern Ireland, UK; and ${ }^{5}$ Northern Ireland Centre for Diet \\ and Health (NICHE), University of Ulster, Northern Ireland, UK
}

\begin{abstract}
The purpose of this study was to examine relationships between aerobic fitness and birthweight in adolescents. A representative cohort of 1015 males and females aged 12 and $15 \mathrm{y}$ was studied, at baseline, with $89 \%$ of the 12 -y-olds being re-examined 3 y later.

The main outcome measures were an index of aerobic fitness, measured in laps completed at voluntary exhaustion by a twenty-metre shuttle run test, and recorded birthweight. Multiple linear regression, with and without adjustment for known and potential confounding variables, was performed to examine associations between fitness and birthweight. Birthweight and aerobic fitness were positively related so that for each $\mathrm{kg}$ decrease in birthweight, there was a mean ( $95 \%$ confidence interval) decrease in fitness score of $4.84(0.35$ to 9.33$)$ laps and 3.21 (0.32 to 6.10) laps, in 12-y-old boys and girls respectively. This relationship is of a similar order to the strength of association between birthweight and adult blood pressure previously reported. Associations between birthweight and physical fitness at the age of 15 were weaker and were not significant.

Our findings suggest that aerobic fitness may be involved in mediating the association between birthweight and cardiovaseular disease risk later in life. The weakening of the association between birthweight and litness between the ages of 12 and $15 \mathrm{y}$ is similar to the weaker associations between birthweight and blood pressure seen among adoleseents compared to younger children. We are currently re-examining this cohort to see if, as with blood pressure. the association with fitness re-emerges at an older age. Public Health (2001) 115, 373-379.
\end{abstract}

Keywords: fetal growth; fitness; young people; cardiovascular disease

\section{Introduction}

It has recently been hypothesised that fetal undernutrition in middle to late gestation, resulting in disproportionate fetal growth and low birthweight, is associated with increased risk of cardiovascular disease (CVD) in later life.' It is hypothesised that the nutrient and hormonal milieu of the fetus alters gene expression, causing developmental adaptations that lead to permanent changes in physiology and metabolism which, in turn, predispose to chronic disease in later life. ${ }^{2}$ Such fetal 'programming' of adult CVD may be mediated by a number of risk factors which have been shown to be associated with birthweight, including blood pressure, ${ }^{3}$ insulin resistance, ${ }^{4}$ serum lipids, ${ }^{5}$ haemostatic factors ${ }^{6}$ and body fat distribution. ${ }^{7}$ Physical fitness is a strong, independent risk factor for

*Correspondence: CA Boreham, Sports Studies, Faculty of Science, University of Ulster at Jordanstown, Shore Road, Newtownabbey, Co Antrim BT37 OQB, UK.

E-mail: ca.boreham@ulst.ac.uk

Accepted 5 July 2001 cardiovascular and all-cause mortality. ${ }^{8-10}$ This study provides the first comprehensive investigation of the relationship between physical fitness and recorded birthweight, in a representative sample of adolescents from Northern Ireland.

\section{Methods}

\section{The study population}

The Young Hearts Project is a prospective study investigating the development of biological and behavioural risk factors for cardiovascular disease (CVD) in an adolescent population. Details of the study design and sampling procedure have been presented elsewhere. "I In brief, a two stage cluster sampling procedure was used to select a representative sample of schoolchildren aged 12 and 15 , taking into account geographical spread and the different categories of school in Northern Ireland. A target sample size of 250 pupils in each age and sex group was based on the variability observed in the pilot study, ${ }^{12}$ and allowance was made for an expected non-response rate of 
374

approximately $20 \%$. Ethical approval was obtained from the Medical Research Ethical Committee of The Queen's University of Belfast, and written, informed consent was obtained from the parent or guardian and all participating children.

All children were examined at baseline (YHI), and the 12 -y-olds were re-examined $3 y$ later (YHII). At both examinations information was collected on dietary intake, weekday and weekend physical activity, smoking and drinking habits and occupation of the head of the household. Physical fitness, blood pressure, height, weight, skinfold thicknesses and blood lipids were also measured by the same trained investigators throughout the course of the study. Physical fitness was measured by a 20 metre endurance shuttle run test (20-MST), and the number of completed laps at volitional exhaustion was used as an indicator of cardiorespiratory fitness. ${ }^{13}$ Performance in the 20-MST has been shown to correlate well with laboratory tests of maximal oxygen uptake. ${ }^{14}$ A physical activity score was computed taking into account the frequency, intensity and duration of the activities undertaken in a typical school week, and during holidays, resulting in a weighted activity score varying from $0-100 .^{15}$ Biological maturity was visually assessed using Tanner's indices for pubic hair development by an experienced physician attached to the project. ${ }^{16}$ Occupational class of the head of the household was classified according to the Office of Population Censuses and Surveys (1990)..$^{17}$

Students whose birthweight was available from the Child Health System (CHS) records were included in this analysis $(n=931)$. Children born at $<36$ weeks gestation were excluded $(n=29)$. Regression models used all subjects with available covariate information in order to make maximum use of the data, therefore sample sizes vary between models. Restriction of the analysis to a subset of individuals with complete data on all covariates did not materially alter the results.

Variables selected for analysis were: age at examination, fitness score (laps), birthweight, gestational age, height, weight, body mass index (BMI), pubertal development (whether or not reached Tanner stage IV of pubertal development (yes/no)), activity score, smoking one or more cigarettes per week (yes/no), father's occupation (manual/non-manual/unemployed or missing), mother's and father's height. Children born at less than 36 weeks gestation were excluded from the analysis.

\section{Statistical methods}

Baseline characteristics of the six student groups (ie 12 and 15-y-old boys, 12 and 15-y-old girls in YHI; 15-y-old boys and girls in YHII) were examined by tabulations and comparisons of means and proportions.

Univariate associations between birthweight and other variables, and between fitness and other variables were examined using simple linear regression. The association between birthweight and fitness score was further examined using multiple linear regression, with and without adjustment for known and potential confounders. Robust standard errors were calculated, to allow for the clustering of pupils within schools. ${ }^{\text {is }}$ Squared partial correlation coefficients (partial $\mathrm{R}^{2}$ ) were calculated to provide an estimate of the proportion of the variation in fitness scores that is 'explained' by birthweight, after controlling for other variables. The partial correlation coefficients were calculated without regard to the clustering of individuals within schools, and so provide only an approximation as a guide for the reader.

\section{Results}

\section{Response rates}

An overall response rate of $78 \%$ resulted in 1015 subjects being tested. Reasons for non-participation have been reported elsewhere. " There was no recognisable pattern for non-participation likely to influence the associations between risk factors within the sample. Birthweight records from CHS were obtained for 931 (91.7\%) of the cohort members. Complete data on parental height and weight were available for $890(87.7 \%)$ participants.

For YHII, the original cohort of 12 -y-old children were re-examined at the age of $15 \mathrm{y}$ under identical conditions with an $89 \%$ follow-up rate for both sexes. Of the 54 drop outs, nine were refusals, 25 did not participate owing to illness, 17 had moved school in the interim, and three had other reasons.

Relevant characteristics of the subjects who participated in YHI and YHII are shown in Table 1.

Variables associated with birthweight and with fitness score in the YHI subjects are shown in Tables 2 and 3 respectively. Gestational age and maternal height were positively associated with birthweight in all age/sex groups. Males born into higher social classes had higher birthweight, and higher weight at birth was positively related to height and weight at age 12 (in most groups) but there was no association between birthweight and BMI. A significant univariate association between birthweight and fitness score was seen in 12-y-old boys and girls, but not in 15-y-olds. Gestational age and maternal height were inconsistently related to fitness and there was no association between social class at birth and fitness at age 12 or 15 . Higher physical activity score, lower weight and BMI were associated with higher fitness score in all age/sex groups. There was no consistent relationship between height and fitness score.

Multiple linear regression results for the association between birthweight and fitness are shown in Table 4 . In boys aged 12, adjustment for BMI reduced the strength of the birthweight-fitness association (unadjusted coefficient 6.2 (95\% CI 1.3 to 11.0 ), vs 4.4 ( -0.2 to 9.0 ) when adjusted for BMI). Adjusting for mother's or father's height 
approximately $20 \%$. Ethical approval was obtained from the Medical Research Ethical Committee of The Queen's University of Belfast, and written, informed consent was obtained from the parent or guardian and all participating children.

All chilcren were examined at baseline (YHI), and the 12 - $y$-olds were re-examined $3 y$ later (YHII). At both examinations information was collected on dietary intake, weekday and weekend physical activity, smoking and drinking habits and occupation of the head of the household. Physical fitness, blood pressure, height, weight, skinfold thicknesses and blood lipids were also measured by the same trained investigators throughout the course of the study. Physical fitness was measured by a 20 metre endurance shuttle run test (20-MST), and the number of completed laps at volitional exhaustion was used as an indicator of cardiorespiratory fitness. ${ }^{13}$ Performance in the 20-MST has been shown to correlate well with laboratory tests of maximal oxygen uptake. ${ }^{14}$ A physical activity score was computed taking into account the frequency, intensity and duration of the activities undertaken in a typical school week, and during holidays, resulting in a weighted activity score varying from $0-100 .^{15}$ Biological maturity was visually assessed using Tanner's indices for pubic hair development by an experienced physician attached to the project. ${ }^{16}$ Occupational class of the head of the household was classified according to the Office of Population Censuses and Surveys (1990). ${ }^{17}$

Students whose birthweight was available from the Child Health System (CHS) records were included in this analysis $(n=931)$. Children born at $<36$ weeks gestation were excluded $(n=29)$. Regression models used all subjects with available covariate information in order to make maximum use of the data, therefore sample sizes vary between models. Restriction of the analysis to a subset of individuals with complete data on all covariates did not materially alter the results.

Variables selected for analysis were: age at examination, fitness score (laps), birthweight, gestational age, height, weight, body mass index (BMI), pubertal development (whether or not reached Tanner stage IV of pubertal development (yes/no)), activity score, smoking one or more cigarettes per week (yes/no), father's occupation (manual/non-manual/unemployed or missing), mother's and father's height. Children born at less than 36 weeks gestation were excluded from the analysis.

\section{Statistical methods}

Baseline characteristics of the six student groups (ie 12 and 15-y-old boys, 12 and 15-y-old girls in YHI; 15-y-old boys and girls in YHII) were examined by tabulations and comparisons of means and proportions.

Univariate associations between birthweight and other variables, and between fitness and other variables were examined using simple linear regression. The association between birthweight and fitness score was further examined using multiple linear regression, with and without adjustment for known and potential confounders. Robust standard errors were calculated, to allow for the clustering of pupils within schools. ${ }^{18}$ Squared partial correlation coefficients (partial $R^{2}$ ) were calculated to provide an estimate of the proportion of the variation in fitness scores that is 'explained' by birthweight, after controlling for other variables. The partial correlation coefficients were calculated without regard to the clustering of individuals within schools, and so provide only an approximation as a guide for the reader.

\section{Results}

\section{Response rates}

An overall response rate of $78 \%$ resulted in 1015 subjects being tested. Reasons for non-participation have been reported elsewhere." There was no recognisable pattern for non-participation likely to influence the associations between risk factors within the sample. Birthweight records from CHS were obtained for 931 (91.7\%) of the cohort members. Complete data on parental height and weight were available for $890(87.7 \%)$ participants.

For YHII, the original cohort of 12 -y-old children werc re-examined at the age of $15 \mathrm{y}$ under identical conditions with an $89 \%$ follow-up rate for both sexes. Of the 54 drop outs, nine were refusals, 25 did not participate owing to illness, 17 had moved school in the interim, and three had other reasons.

Relevant characteristics of the subjects who participated in YHI and YHII are shown in Table 1.

Variables associated with birthweight and with fitness score in the YHI subjects are shown in Tables 2 and 3 respectively. Gestational age and maternal height were positively associated with birthweight in all age/sex groups. Males born into higher social classes had higher birthweight, and higher weight at birth was positively related to height and weight at age 12 (in most groups) but there was no association between birthweight and BMI. A significant univariate association between birthweight and fitness score was seen in 12-y-old boys and girls, but not in 15-y-olds. Gestational age and maternal height were inconsistently related to fitness and there was no association between social class at birth and fitness at age 12 or 15 . Higher physical activity score, lower weight and BMI were associated with higher fitness score in all age/sex groups. There was no consistent relationship between height and fitness score.

Multiple linear regression results for the association between birthweight and fitness are shown in Table 4 . In boys aged 12, adjustment for BMI reduced the strength of the birthweight-fitness association (unadjusted coefficient 6.2 (95\% CI 1.3 to 11.0 ), vs 4.4 ( -0.2 to 9.0 ) when adjusted for BMI). Adjusting for mother's or father's height 
Table 1 Characteristics of subjects in Young Hearts I and II (YHI and YHII) by age group and sex (standard deviations in brackets)

\begin{tabular}{|c|c|c|c|c|c|c|}
\hline & \multicolumn{4}{|c|}{$\mathrm{YHI}$} & \multicolumn{2}{|c|}{ YHII } \\
\hline & $\begin{array}{c}\text { Males, } 12 y \\
n=240\end{array}$ & $\begin{array}{c}\text { Females, } 12 \text { y } \\
n=252\end{array}$ & $\begin{array}{c}\text { Males, } 15 y \\
n=244\end{array}$ & $\begin{array}{c}\text { Females, } 15 y \\
n=250\end{array}$ & $\begin{array}{c}\text { Males, } 15 y \\
n=179\end{array}$ & $\begin{array}{c}\text { Females, } 15 \mathrm{y} \\
n=185\end{array}$ \\
\hline Mean age $(y)$ & $12.5(0.3)$ & $12.5(0.3)$ & $15.5(0.3)$ & $15.5(0.3)$ & $15.6(0.4)$ & $15.6(0.4)$ \\
\hline Mean fitness score (laps) & $59.1(19.0)^{\mathrm{a}}$ & $44.1(13.1)$ & $79.3(21.0)^{\mathrm{a}}$ & $45.3(13.6)$ & $82.5(21.1)^{\mathfrak{a}}$ & $46.7(15.3)$ \\
\hline Mean gestation (wk) & $39.6(1.2)$ & $39.7(1.0)$ & $39.6(1.2)$ & $39.7(1.2)$ & $39.6(1.3)$ & $39.7(1.1)$ \\
\hline Mean birthweight ( $g$ ) & $3438(502)^{\mathrm{a}}$ & $3312(467)$ & $3522(526)^{\mathrm{a}}$ & $3338(502)$ & $3452(511)$ & $3333(468)$ \\
\hline Mean activity score & $33.2(14.6)$ & $24.3(13.4)$ & $27.1(15.4)^{\mathrm{a}}$ & $17.4(11.9)$ & $26.3(13.9)^{a}$ & $16.6(10.5)$ \\
\hline Mean height $(\mathrm{cm})$ & $149.8(8.0)$ & $150.8(7.5)$ & $168.9(7.4)^{\mathrm{a}, \mathrm{b}}$ & $160.6(5.9)$ & $170.7(7.3)^{\mathrm{a}}$ & $161.2(6.1)$ \\
\hline Mean weight $(\mathrm{kg})$ & $42.8(9.7)$ & $43.8(9.1)$ & $58.6(9.7)^{b}$ & $56.7(8.6)$ & $61.5(11.8)^{\mathbf{a}}$ & $56.1(8.8)$ \\
\hline Mean BMI $\left(\mathrm{kg} / \mathrm{m}^{2}\right)$ & $18.9(3.5)$ & $19.2(3.0)$ & $20.5(2.5)$ & $22.0(3.2)$ & $21.0(3.3)$ & $21.6(3.1)$ \\
\hline$\%$ smokers & 2.8 & 1.3 & 21.3 & 15.4 & 23.7 & 19.7 \\
\hline$\%$ from manual social classes & 37.1 & 30.4 & 35.0 & 33.8 & 35.8 & 27.6 \\
\hline$\%$ reached stage IV pubic hair status & 4.2 & 29.3 & 82.4 & $97.8^{\mathrm{b}}$ & 85.0 & 90.8 \\
\hline
\end{tabular}

"Significantly different from females of same age group $(P<0.01)$.

${ }^{b}$ Significantly different from pupils of same sex and age group in YHII $(P<0.05)$.

Table 2 Single variable linear regression analysis showing the relationship between birthweight and other variables in males and females aged 12 and 15 in $\mathrm{YHI}$

\begin{tabular}{lcccc} 
& & \multicolumn{4}{c}{ Regression coefficient in $\mathrm{g}(95 \% \mathrm{Cl})$} \\
\cline { 2 - 5 } Explanatory variable & Males, 12y & Females, $12 \mathrm{y}$ & Males, 15y & Females, $15 \mathrm{y}$ \\
\hline Gestational age (wks) & $162(113$ to 212$)$ & $98(37$ to 156$)$ & $166(133$ to 199$)$ & $99(15$ to 184$)$ \\
Height $(\mathrm{cm})$ & $11(-2$ to 23$)$ & $15(9$ to 20$)$ & $11(-1$ to 23$)$ & $24(12$ to 36$)$ \\
Weight $(\mathrm{kg})$ & $1(-6$ to 8$)$ & $7(3$ to 11$)$ & $7(-4$ to 17$)$ & $9(0$ to 18$)$ \\
BMI $\left(\mathrm{kg} / \mathrm{m}^{2}\right)$ & $-13(-35$ to 9$)$ & $3(-9$ to 15$)$ & $15(-18$ to 49$)$ & $4(-14$ to 21$)$ \\
Reached stage IV pubertal status & $-19(-248$ to 210$)$ & $-29(-183$ to 124$)$ & $-56(-240$ to 128$)$ & $27(-62$ to 116$)$ \\
Mother's height $(\mathrm{cm})$ & $14(2$ to 27$)$ & $22(12$ to 32$)$ & $19(11$ to 28$)$ & $19(9$ to 29$)$ \\
Father's height $(\mathrm{cm})$ & $7(-10$ to 24$)$ & $7(-1$ to 15$)$ & $10(-3$ to 23$)$ & $6(-4$ to 15$)$ \\
Father's occupation manual & $-211(-385$ to -39$)$ & $-57(-232$ to 118$)$ & $-184(-405$ to 36$)$ & $-39(-160$ to 82$)$ \\
\hline
\end{tabular}

"Standard errors adjusted to account for clustering of pupils within schools.

${ }^{\mathrm{b} C o m p a r i s o n ~ g r o u p ~ a r e ~ t h o s e ~ w h o ~ h a d ~ n o t ~ r e a c h e d ~ s t a g e ~ I V ~ p u b e r t a l ~ s t a t u s . ~}$

Table 3 Simple linear regression analysis showing the relationship between fitness score and birthweight and other variables in males and females aged 12 and 15 in YHI

\begin{tabular}{|c|c|c|c|c|}
\hline \multirow[b]{2}{*}{ Explanatory variable } & \multicolumn{4}{|c|}{ Regression coefficient in laps $\left(95 \% \mathrm{CI}^{\mathrm{i}}\right)$} \\
\hline & Males, $12 \mathrm{y}$ & Females, $12 \mathrm{y}$ & Males, $15 \mathrm{y}$ & Females, $15 \mathrm{y}$ \\
\hline Birthweight $(\mathrm{kg})$ & $6.2(1.25$ to 11.0$)$ & $4.3(1.0$ to 7.6$)$ & $-0.3(-6.7$ to 6.0$)$ & $-0.5(-5.3$ to 4.4$)$ \\
\hline Gestational age (wks) & $1.1(-1.4$ to 3.6$)$ & $1.2(-0.2$ to 2.5$)$ & $-0.6(-2.3$ to 2.4$)$ & $1.8(0.6$ to 3.0$)$ \\
\hline Height $(\mathrm{cm})$ & $-0.2(-0.4$ to 0.1$)$ & $0.0(-0.3$ to 0.3$)$ & $0.4(-0.2$ to 1.0$)$ & $0.1(-0.2$ to 0.4$)$ \\
\hline Weight $(\mathrm{kg})$ & $-0.9(-1.0$ to -0.8$)$ & $-0.4(-0.6$ to -0.1$)$ & $-0.2(-0.7$ to 0.3$)$ & $-0.4(-0.7$ to -0.1$)$ \\
\hline $\mathrm{BMI}\left(\mathrm{kg} / \mathrm{m}^{2}\right)$ & $-2.8(-3.5$ to -2.0$)$ & $-1.6(-2.3$ to -0.8$)$ & $-1.7(-2.8$ to -0.6$)$ & $-1.2(-2.1$ to -0.3$)$ \\
\hline Age $(y)$ & $9.8(1.8$ to 17.8$)$ & $5.3(-3.1$ to 13.7$)$ & $0.4(-14.2$ to 15.1$)$ & $-2.4(-8.4$ to 3.6$)$ \\
\hline Stage IV pubertal status ${ }^{\mathrm{b}}$ & $5.0(-4.5$ to 14.4$)$ & $-1.7(-5.9$ to 2.5$)$ & $15.1(7.4$ to 22.9$)$ & $5.9(0.8$ to 10.9$)$ \\
\hline Activity score & $0.4(0.1$ to 0.6$)$ & $0.2(0.1$ to 0.4$)$ & $0.3(0.0$ to 0.6$)$ & $0.2(0.1$ to 0.4$)$ \\
\hline Smoking & $-20.0(-33.7$ to -6.4$)$ & $5.3(-6.1$ to 16.8$)$ & $0.4(-14.2$ to 15.1$)$ & $-2.4(-8.4$ to 3.6$)$ \\
\hline Mother's height $(\mathrm{cm})$ & $0.4(-0.1$ to 1.0$)$ & $0.3(0.0$ to 0.5$)$ & $-0.1(-0.5$ to 0.3$)$ & $-0.1(-0.5$ to 0.3$)$ \\
\hline Father's height $(\mathrm{cm})$ & $0.4(-0.1$ to 1.0$)$ & $-0.1(-0.4$ to 0.2$)$ & $-0.2(-0.8$ to 0.4$)$ & $0.0(0.3$ to 0.3$)$ \\
\hline Father's occupation manual & $-2.0(-6.7$ to 2.8$)$ & $-1.2(-5.6$ to 3.2$)$ & $-3.7(-9.2$ to 1.8$)$ & $-1.6(-5.2$ to 2.0$)$ \\
\hline
\end{tabular}

${ }^{a}$ Standard errors adjusted to account for clustering of pupils within schools.

${ }^{\circ}$ Comparison group are those who had not reached stage IV pubertal status. 
Table 4 Multiple linear regression, showing predicted change in mean fitness score per kg increase in birthweight for males and females aged 12 and 15 in $\mathrm{YHI}$

\begin{tabular}{lllrr}
\hline & & \multicolumn{2}{l}{ Regression coefficient in laps $\left(95 \% \mathrm{CI}^{\mathrm{a}}\right)$} \\
\cline { 2 - 5 } Model controlling for: & \multicolumn{1}{c}{ Males, $12 \mathrm{y}$} & Females, $12 \mathrm{y}$ & \multicolumn{1}{c}{ Males, $15 \mathrm{y}$} & Females, $15 \mathrm{y}$ \\
\hline Unadjusted & $6.2(1.3$ to 11.0$)$ & $4.3(1.0$ to 7.6$)$ & $-0.3(-6.7$ to 6.0$)$ & $-0.5(-5.3$ to 4.4$)$ \\
Gestational age & $6.1(0.5$ to 11.6$)$ & $3.9(0.6$ to 7.2$)$ & $-0.4(-5.9$ to 5.1$)$ & $-1.5(-6.0$ to 3.0$)$ \\
Height & $6.8(1.1$ to 12.6$)$ & $4.5(1.1$ to 7.9$)$ & $-1.2(-8.7$ to 6.3$)$ & $-0.8(-5.7$ to 4.1$)$ \\
Weight & $6.5(-0.7$ to 12.3$)$ & $5.4(1.5$ to 9.3$)$ & $0.1(-7.0$ to 7.2$)$ & $0.6(-4.3$ to 5.4$)$ \\
BMI & $4.4(-0.2$ to 9.0$)$ & $4.5(0.9$ to 8.1$)$ & $0.3(-6.3$ to 6.9$)$ & $-0.3(-4.9$ to 4.3$)$ \\
Age & $5.8(1.1$ to 10.6$)$ & $4.2(1.2$ to 7.1$)$ & $-0.3(-6.7$ to 6.1$)$ & $-0.3(-5.0$ to 4.3$)$ \\
Stage IV pubertal status & $6.2(1.4$ to 11.0$)$ & $4.2(1.0$ to 7.5$)$ & $0.1(-5.1$ to 5.4$)$ & $-0.5(-5.3$ to 4.4$)$ \\
Activity score & $6.2(1.9$ to 10.5$)$ & $4.1(1.0$ to 7.3$)$ & $-0.5(-7.7$ to 6.6$)$ & $-0.2(-5.0$ to 4.7$)$ \\
Smoking & $6.2(1.3$ to 11.1$)$ & $4.4(1.0$ to 7.9$)$ & $0.2(-5.9$ to 6.3$)$ & $-0.4(-5.5$ to 4.7$)$ \\
Mother's height & $4.6(0.2$ to 9.1$)$ & $3.7(1.0$ to 6.4$)$ & $-0.1(-6.6$ to 6.4$)$ & $-0.7(-6.7$ to 5.4$)$ \\
Father's height & $4.9(0.8$ to 9.0$)$ & $4.6(1.0$ to 8.3$)$ & $-1.4(-7.8$ to 5.1$)$ & $0.0(-6.2$ to 6.3$)$ \\
Father's occupation & $6.4(1.7$ to 11.0$)$ & $4.4(1.2$ to 7.5$)$ & $-0.3(-7.0$ to 6.4$)$ & $-0.6(-5.7$ to 4.4$)$ \\
Gestational age, height, & $5.3(1.0$ to 9.5$)$ & $3.3(0.6$ to 5.9$)$ & $-0.6(-5.6$ to 4.4$)$ & $0.2(-4.6$ to 5.1$)$ \\
$\quad$ weight, BMI, age, Stage & & & & \\
IV pubertal status, activity & & & & \\
score, mother's height, & & & & \\
father's height, father's & & & & \\
occupation & & & & \\
\hline
\end{tabular}

"Standard errors adjusted to account for clustering of pupils within schools.

also reduced the strength of the association, but since these models were based on fewer subjects (owing to missing data), this difference may be partly owing to chance. Adjusting for other potential confounders individually had little effect on the regression coefficient for birthweight, but including all confounders together reduced the strength of the birthweight-fitness association although it remained significant in 12-y-old boys $(5.3(1.0$ to 9.5$)$ ) and $12-y$ old girls (3.3 (0.6 to 5.9)). Examination of partial correlation coefficients suggested that after controlling for the effects of other variables, variation in birthweight 'explained' about $2.4 \%$ of the variation in fitness score for 12 -y-old boys, and $1.5 \%$ for 12 -y-old girls. Birthweight was not a significant predictor of fitness score among $15-y-$ old boys and girls. Among 15-y-olds, there was no significant association between birthweight and fitness, even after adjustment for potential confounders.

Longitudinal data on birthweight, fitness and other explanatory variables were available for 181 boys and 187 girls at ages 12 and 15 . In boys, the positive association between birthweight and fitness seen at age 12 was considerably weaker and no longer significant by age 15 , after adjusting for potential confounders (Table 5). In girls the association was weaker than for males at age 12 and had disappeared at age 15 .

\section{Discussion}

As far as we are aware this is the first study to demonstrate associations between birthweight and cardiorespiratory fitness in a representative population sample, although resting

Table 5 Multiple linear regression, showing relationship between birthweight and fitness score in the same 368 individuals at age 12 (in YHI) and 15 (in YHII)

\begin{tabular}{|c|c|c|c|c|}
\hline \multirow[b]{3}{*}{ Model controlling for: } & \multicolumn{4}{|c|}{ Regression coefficient in laps $\left(95 \% \mathrm{CI}^{\mathrm{a}}\right)$} \\
\hline & \multicolumn{2}{|c|}{ Males $(n=180)$} & \multicolumn{2}{|c|}{ Females $(n=188)$} \\
\hline & Age 12 & Age 15 & Age 12 & Age 15 \\
\hline Unadjusted & $6.3(0.3$ to 12.3$)$ & $3.6(-1.5$ to 8.7$)$ & $3.4(-1.1$ to 7.9$)$ & $1.6(-3.2$ to 6.4 \\
\hline $\begin{array}{l}\text { Gestational age, height, weight, BMI, } \\
\text { age, Stage IV pubertal status, activity } \\
\text { score, smoking, mother's height, } \\
\text { father's height, father's occupation }\end{array}$ & $6.4(0.4$ to 12.5$)$ & $1.3(-5.0$ to 7.7$)$ & $3.0(-0.8$ to 6.8$)$ & $1.0(-2.8$ to 4.8$)$ \\
\hline
\end{tabular}

astandard errors adjusted to account for clustering of pupils within schools. 
heart rate, which may be a proxy for fitness, has been shown to be raised in subjects with a low birthweight. ${ }^{19}$ Higher birthweight was independently associated with higher fitness score at age 12 but the relationship was perturbed between the ages of 12 and 15, especially in girls. This is in keeping with the association between birthweight and blood pressure; birthweight predicts prepubertal blood pressure ${ }^{20}$ but the association is less obvious in adolescents. ${ }^{21}$ In this study the disturbance of the birthweight/fitness relationship between these ages appeared to be unrelated to pubertal development as measured by Tanner's pubic hair staging. Pubertal assessment is difficult and it is possible that the method used or its application in this population did not result in appropriate classification of pubertal stage.

An important feature of the present study was the degree of control exerted over possible confounding factors. For example, several authors ${ }^{22,23}$ have reported that physical work capacity is reduced in children who suffered from undernutrition in their early development. However, as Haas et $\mathrm{al}^{24}$ report, this apparent effect of past stunting on later physical fitness is reduced or eliminated after expressing work capacity relative to body mass. Similarly, levels of habitual physical activity have been shown to influence cardiorespiratory fitness in the present cohort, ${ }^{4}$ while fatness, ${ }^{25}$ smoking $^{26}$ and stage of maturation ${ }^{27}$ have all been shown to influence fitness in adolescents. The association we observed was independent of these factors.

Fitness is, at least in part, genetically determined. ${ }^{28}$ If genes which determine fitness also govern birthweight the finding which we have observed may be genetically determined and unrelated to factors acting during the intrauterine period. We were unable to thoroughly examine this possibility but adjusting the relationship between birthweight and fitness for proxies for genetic influences on birthweight and fitness (maternal and paternal height) had little effect on observed regression coefficients.

It therefore appears that, along with other established risk factors for CVD, long term physical fitness may be partly 'programmed' by environmental influences acting at critical stages in early life. The nature of these changes, which could include modification of gene expression, permanent change in cell numbers or modification of organ structure is unknown but several plausible biological mechanisms present themselves. Cardiorespiratory fitness is largely dependent upon the rate at which oxygen can be consumed during maximal exercise. Limiting factors in this process may be centrally located (particularly cardiac output, which is largely determined by left ventricular mass) or peripherally located, as the arterio-venous oxygen difference - determined by the oxidative capacity of the exercising muscles. ${ }^{29}$

Heart muscle may be particularly sensitive to underfeeding at early stages of development and left ventricular mass may be programmed in utero. It is known that low birthweight babies may have persisting defects in their growth-hormone and insulin-like growth factor (IGF-1) axis, suggesting a degree of growth-hormone resistance. ${ }^{30}$ Postnatally, the growth-hormone axis influences cardiovascular function. Both growth-hormone and IGF-1 increase cardiac output, stimulate ventricular growth and influence angiogenesis, while IGF-1 exerts strong anabolic effects on cardiac muscle. ${ }^{31}$

Fetal undernutrition may also have long-lasting effects upon skeletal muscle which could conceivably reduce cardiovascular fitness in adolescence. Studies using magnetic resonance spectroscopy indicate that adults who were thin at birth had reduced rates of muscle glycolysis, resulting in more rapid fatigue than control subjects. This could indicate persistence of a fetal glucose sparing adaptation into later life. ${ }^{32}$ Possible corroborating evidence for this suggestion comes from a recent study by Small et al ${ }^{33}$ who reported a reduced anaerobic performance in adolescents who had extremely low birthweights $(<1000 \mathrm{~g}$ ) compared with nomal birthweight controls. There is also some suggestion ${ }^{34}$ that a deficiency of placental regulation in small-for-gestational-age children may interfere with normal muscle fibre-type differentiation. However, there is no human experimental evidence for this, and little support from animal models. For example, Boreham et $a^{35}$ employed a model of chronic dietary restriction imposed soon after weaning in rats. Muscle fibre-type differentiation was minimally affected, and although the microcirculation of muscle, specifically, the capillary/fibre ratio, was reduced, this was only in proportion to the reduction in muscle fibre size.

At least part of the explanation for the poorer aerobic fitness displayed by our lower birthweight adolescents may lie in their level of motor co-ordination. The cerebellum is involved with the co-ordination of somatic motor activity and mechanisms associated with the maintenance of posture and equilibrium. ${ }^{36}$ It develops during the last months of pregnancy, and its size reflects fetal age. ${ }^{37}$ Although we did not measure co-ordination in our subjects, several authors have reported reduced co-ordination in children of low bithweight ${ }^{38.39}$ and at least one group ${ }^{40}$ have reported lower running economy in such children at the age of $7-12 y$, suggesting that this may be related to an immature muscular co-ordination. Accordingly, it is possible that the earlier fatigue associated with lower birthweight reported in the present study, is a reflection of the additional energy requirements of performing the running test with deficient limb co-ordination.

Our findings suggest that fitness may be involved in mediating the association between birthweight and CVD risk in adulthood. A standard deviation difference in birthweight is associated with about a $1 / 5$ th standard deviation difference in fitness in 12-y-olds. This is of a similar order to the strength of association between birthweight and adult blood pressure. The weakening of the association between birthweight and fitness when these 12-y-olds had become 15 is similar to the weaker cross-sectional associations between birthweight and blood pressure seen among adolescents and young adults compared to younger children 
and older adults. We are currently re-examining this cohort to see if, as with blood pressure, the association with fitness re-emerges at an older age. If so the influence of early development on physical fitness justifies more detailed investigation, in particular whether modifiable aspects of the intrauterine environment are responsible for the association, or if it reflects a common genetic influence on birthweight and fitness. The importance of uncovering determinants of physical fitness lies in the protection it affords against CVD and other chronic diseases in adulthood.

\section{Acknowledgements}

\section{Funding sources}

The British Heart Foundation; The Wellcome Trust; Northern Ireland Chest, Heart and Stroke A.ssociation.

\section{References}

1 Barker DJP. Fetal origins of coronary heart disease. Br Med J 1995; 311: 171-174.

2 Godfrey JM. Maternal regulation of fetal development and health in later life. Eur J Obstet Gynecol Reprod Biol 1998; 78: $14 !-150$

3 Martyn CN et al. Growth in utero, adult blood pressure and arterial compliance. Br Heart $J$ 1995; 73: 116-121.

4 Phillips DIW. Insulin resistance as a programmed response to fetal undernutrition. Diabetologia 1996; 39: 1119-1122.

5 Barker DJP, Martyn CN, Osmond C, Hales CN, Fall CHD. Growth in utero and serum cholesterol concentrations in adult life. Br Med $J$ 1993; 307: 1524-1527.

6 Martyn CN, Meade TW, Stirling Y, Barker DJP. Plasma concentrations of fibrinogen and factor VII in adult and their relation to intrauterine growth. Br J Haematol 1995; 89: 142146

7 Barker M, Robinson S, Osmond C, Barker DJP. Birthweight and body fat distribution in adolescent girls. Arch Dis Child 1997; 77: 381-383.

8 Erikssen G, Liestøl K, Bjørnholt J, Thaulow E, Sandvik L, Erikssen J. Changes in physical fitness and changes in mortality. Lancet 1998; 352: 759-762.

9 Sandvik L, Erikssen J, Thaulow E, Erikssen G, Mundal R, Rodahl K. Physical fitness as a predictor of mortality among healthy middle-aged Norwegian men. New Engl J Med 1993; 328: $533-537$.

10 Blair SN et al. Influences of cardiorespiratory fitness and other precursors on cardiovascular disease and all-cause mortality in men and women. JAMA 1996; 276; 205-210.

11 Boreham C, Savage JM, Primrose D, Cran G, Strain J. Coronary risk factors in schoolchildren. Arch Dis Child 1993; 68: $182-186$

12 Primrose ED, Savage JM, Boreham CAG, Cran GW, Strain JJ. Coronary risk factors in Belfast schoolchildren. Irish Med J 1993; 86: 17-19.

13 Boreham C; Paliczka VJ, Nichols AK. A comparison of the PWC170 and 20-MST tests of aerobic fitness in adolescent schoolchildren. J Sports Med Phy Fitness 1990; 30: 19-23.

14 Van Mechelen W, Hlobil H, Kemper HCG. Validation of two running tests as an estimate of maximal aerobic power in children. Eur J Appl Physiol 1986; 55: 503-506.

15 Riddoch C, Savage JM, Murphy N, Cran G, Boreham C. Long term health implications of fitness and physical activity patterns. Arch Dis Child 1991; 66: 1426-1433.

16 Tanner JM. Growth at Adolescence, 2nd Ed. Blackwell Scientific: Oxford, UK, 1962, pp 28-40.

17 A publication of the Government Statistical Service Standard Occupational Classification (Vols, 1, 2 and 3). Office of Population Census and Surveys. HMSO: London, 1990.

18 Rogers WH. Regression standard errors in clustered samples. Stata Technical Bulletin 1993; 13: 19-23.

19 Phillips DIW and Barker DJP. Association between low birthweight and high resting pulse in adult life: is the sympathetic nervous system involved in programming the insulin resistance syndrome? Diabetic Med 1997; 14: $673-677$.

20 Whincup PH, Cook DG, Papacosta O. Do maternal and intrauterine factors influence blood pressure in childhood? Arch Dis Child 1992; 67: 1423-1429.

21 Seidman DS, Laor A, Gale R, Stevenson DK, Mashiach S, Danon YL. Birth weight, current body weight, and blood pressure in late adolescence. $\mathrm{Br}$ Med $J$ 1991; 302: 12351237.

22 Spurr GB. Body size, physical work capacity and productivity in hard work: is bigger better? In: Linear Growth Retardation in Less Developed Countries. Nestle Nutrition Workshop Series. J Waterlow (ed). Vevey/Raven Press: New York, 1988, Vol 14, pp 215-243.

23 Satyanarayana K, Naidu AN, Narasinga Rao BS. Nutritional deprivation in childhood and the body size, activity and physical work capacity of young boys. All J Clin Nutr. 1979; 32: 1769-1775.

24 Haas JD, Murdoch S, Rivera J, Martorell R. Early nutrition and later physical work capacity. Nutr Rev 1996; 54: 541 548.

25 Hager RL, Tucker LA, Seljaas GT. Aerobic fitness, blood lipids and body fat in children. Am J Public Health 1995; 85: $1702-1706$.

26 Boreham C, Twisk J, Van Mechelen W, Savage M, Strain J, Cran G. Relationships between the development of biological risk factors for coronary heart disease and lifestyle parameters during adolescence: The Northern Ireland Young Hearts Project. Public Health 1999; 113: 7-12.

27 Baxter-Jones A, Goldstein H, Helms P. The development of aerobic power in young athletes. $J$ Appl Physiol 1993; 75: $1160-1167$

28 Montgomery HE et al. Association of angiotensin-converting enzyme gene I/D polymorphism with change in left ventricular mass in response to physical training. Circulation 1997; 96: $741-747$.

29 Wilmore JH, Costill DL. Physiology of Sport and Exercise. Human Kinetics: Champaign, IL, 1994, pp 214-238.

30 Job JC, Chatelain P, Rochiccioli P, Porte C, Oliver M, Sagard $\mathrm{L}$. Growth hormone response to a bolus injection of 1-44 growth-hormone-releasing hormone in very short children with intrauterine onset growth failure. Horm Res 1999; 33: $161-165$.

31 Barker DJP, Gluckman PD, Godfrey KM, Harding KE, Owens JA, Robinson JS. Fetal nutrition and cardiovascular disease in adult life. Lancet 1993; 341: 938-941. 
32 Taylor DJ et al. A relationship between impaired fetal growth and reduced muscle glycolysis revealed by ${ }^{31} \mathrm{P}$ magnetic resonance spectroscopy. Diabetologia 1995; 38: $1205-$ 1212.

33 Small E, Bar-Or O, Van Mil E, Saigal S. Muscle function of 11- to 17-year old children of extremely low birthweight. Pediatr Exerc Sci 1998; 10: 327-336.

34 Touwen BCL, Hadders-Algra M, Huiges HJ. Hypotonia at six years in prematurely-born or small-for-gestational-age children. Early Hum Dev 1988; 17: 79-88.

35 Boreham C, Watt PW, Williams PE, Merry BJ, Goldspink G, Goldspink DF. Effects of ageing and chronic dietary restriction on the morphology of fast and slow muscles of the rat. $J$ Anat 1988; 157: 111-125.
36 Volpe JJ. Neurology of the Newborn, 3rd Ed. Harcourt Brace and Company: Philadelphia, 1995, pp 586.

37 Mcleary RD, Kuhns LR, Barr M. Utrasonography of the fetal cerebellum. Radiology 1984; 151: 439.

38 Elliman AM, Bryan CM, Elliman AD, Walker J, Harvey DR. Co-ordination of low birthweight $7 \mathrm{y}$-olds. Acta Paediatr Scand 1991; 80: 316-322.

39 Soorani-Lunsing RJ, Hadders-Algra M, Huisjes HJ, Touwen BCL. Minor neurological dysfunction after the onset of puberty: association with perinatal events. Early Hum Dev 1993; 33: $71-80$.

40 Baraldi E, Zanconato S, Zorzi C, Santuz P, Benini F, Zacchello F. Exercise performance in very low birthweight children at the age of 7-12 y. Pediatrics $1991 ; 150$ : 713-716. 